\title{
Universal contactless converters of monitoring and control systems in water power industry
}

\author{
Anatoliy Plakhtiev ${ }^{1 *}$, Gayratjon Gaziev ${ }^{2}$, Yaxyojon Meliboev ${ }^{1}$, Odil Doniyorov ${ }^{1}$, Davron \\ Norholboyev ${ }^{1}$, and Jasur Ibragimov ${ }^{1}$ \\ ${ }^{1}$ Tashkent institute of irrigation and agricultural mechanization engineers, Tashkent, Uzbekistan \\ ${ }^{2}$ Triple Point Engineering LLC, Tashkent, Uzbekistan
}

\begin{abstract}
The paper substantiates the need to use non-contact conversion and measurement of large direct currents using non-destructive magneto modulation non-contact ferromagnetic transducers of increased sensitivity for the needs of land reclamation, irrigation, industry, metallurgy and, in general, agriculture and water management; the results of their design development are presented. It is shown that the developed converter, in contrast to the known ones, has increased accuracy and sensitivity, a technologically advanced design and small weight and dimensions with low material consumption and cost. The issues of reliability of magnetic modulation contactless converters are considered. The results of their research have been obtained. It is shown that the reliability of wide-range magneto modulation contactless converters of large direct currents is equal to 0.998 and taking into account catastrophic failures, their total reliability is 0.9969 . The developed converter can be widely used in electrical systems in land reclamation and irrigation, in water supply, industry, railway transport, science, technology and for checking electrical meters at their installation site.
\end{abstract}

\section{Introduction}

In the electric power industry of solar power plants, solar power plants, during direct conversion of solar energy into electrical energy using photo- and thermoelectric conversions, renewable energy sources, laser systems, in power systems for focusing and rotary electromagnets of particle accelerators, at many domestic enterprises, railway transport, in metallurgy, as well as in the control and management systems in irrigation and land reclamation, there is a problem of non-destructive quality control of industrial products and the functioning of technological processes [1]. All these processes for obtaining industrial products and the functioning of technological processes are characterized by the fact that their main parameter of quality control is a large direct current (LDC), the value of which is used to judge the quality of industrial products and the functioning of technological processes. Its value is controlled by several measuring transducers (MT) [2].

\footnotetext{
*Corresponding author: a.plakhtiev@mail.ru,
} 
The problem of increasing the accuracy, reliability and efficiency of control of these technological processes is urgent, which together will improve the quality and quantity of industrial products and the stability of technological processes (TP) $[3,4]$.

It was revealed that the instability of the current control systems, the presence of additional resistances due to the oxidation of contacts lead to a decrease in the performance of industrial facilities and devices, as well as powerful pumps in agriculture and water management, and often to their downtime, and large voltage drops on the shunts lead to unjustified power losses [5-9].

As a result of the analysis of the conducted studies, an urgent need was revealed at many objects and enterprises, as well as in the agriculture and water management of the Republic of Uzbekistan, for non-destructive contactless control of BPT with a value from 30 A to 30 kA using both portable and stationary power supplies with an error of 1-3\%, using in some cases multi-limit IP of non-destructive quality control [9].

As a result of the analysis, it was found that none of the known and considered IP of nondestructive quality control satisfies the requirements in full, which to a greater extent satisfies the listed requirements, mainly magnet-modulation IP of non-destructive quality control [11-30]. Therefore, increasing the efficiency and expanding the functionality of noncontact wide-range magnetic modulation ferromagnetic converters of large direct currents with distributed magnetic parameters (DCBD) for non-destructive quality control of industrial products and the functioning of technological processes for monitoring and control systems is an important necessity.

\section{Materials and Methods}

The authors have developed several multidisciplinary monitoring systems, including new effective universal creative wide-range non-contact ferromagnetic converters of large direct currents with distributed magnetic parameters for a wide range of different monitoring and control systems that differ from the known ones in an extended controlled range with small dimensions and weight, increased accuracy, simplicity and the manufacturability of the design with its low material consumption and cost, the multi-range of the converter, as well as the possibility of contactless control of constant rectified, pulsating and impulse currents, as well as for checking the electric meters at their installation site [9].

Let us consider the most typical design of the developed WNFC - a non-contact widerange magnetic modulation ferromagnetic converter of large direct currents (MWNFC), its features and reliability.

Figure 1 shows the developed MBShPT of monitoring and control systems. It is developed based on the BSPT [10] and is distinguished by increased sensitivity and an extended range of converted currents. MBShPT contains a split closed magnetic circuit 1 , consisting of two identical halves 2 and 3, each of which, in turn, consists of separate ferromagnetic elements made in the form of trapezoids with the same gaps between them. Each ferromagnetic element has two through holes, through each of which a modulation winding is wound, consisting of sections 4 and 5. Sections 4 and 5 are connected in series and accordance with. A measuring winding 6 is wound over the modulation winding between the through holes. All measuring windings are connected in series and closed to the measuring device, (fig. 1 not shown).

To freely wrap around the bus 8 with a controlled current, the closed magnetic circuit 1 is made detachable. The series connection between modulation windings 2 and 3 in the presence of alternating current in them and the location of the measuring windings 6 in the intervals between the through holes in the ferromagnetic elements allowed to carry out longitudinal modulation of the magnetic resistance of the magnetic circuit on the path of the working flow $\Phi$, created by a controlled direct current, and induce an EMF in the measuring windings 6 , depending on the converted direct current. The developed MWNFC can also 
control alternating current. There should be no alternating current in sections 4 and 5 of the modulation winding in this case.

The expansion of the upper limit of the controlled direct current in the developed design of the MBShPT is carried out by increasing the length of the working magnetic flux along the steel of the elements of the magnetic circuit and including transverse and longitudinal air gaps in its path, i.e., making a split magnetic circuit with longitudinally distributed magnetic parameters.

To control the BPT, the detachable magnetic circuit of the MWNFC covers the bus 8 . Due to the modulation ampere-turns, the detachable magnetic circuit is in a saturated state during each half-period of the supply voltage. In this case, the permeability of the magnetic circuit for the longitudinal field created by the controlled current decreases sharply. At the moment when the modulation current passes through zero, the magnetic core permeability rises to the initial value. Thus, with the stability of the modulation ampere turn in the measuring winding, an EMF will be induced doubled frequency, proportional to the controlled current.

With the mutual displacement of halves 2 and 3 of the detachable magnetic circuit MBShPT, the size of the gaps between the trapezoids changes, leading to a change in the whole of the magnetic resistance of the magnetic circuit in the path of the working magnetic flux $\Phi$, created by a controlled direct current. This leads to a change in the limits of the controlled current, i.e. allows you to make MBShPT multi-limit.

For widespread use of MWNFC, it is necessary to determine its reliability.

Reliability is understood as the property of a converter to perform specified functions while maintaining its performance indicators within specified limits under specified operating conditions and conditions for a required period or required operating time [53]. According to the physical nature of manifestations, failures are divided into catastrophic and parametric. In the well-known literature [54 - 56], methods for reducing catastrophic failures of automation elements and devices, including MWNFC, are well developed.

According to their intended purpose, reliability calculations are distinguished at the design stage (predictive) and the test and operation stage (ascertaining). According to the fundamental principles, the calculation of reliability MWNFC divided into elemental (hardware) and functional (parametric). By the nature of the considered failures (sudden, gradual) and taking into account the characteristics of the failures (sudden, gradual, complete, partial, short circuit, open circuit, etc.), real designs MWNFC do not strictly correspond to some one model of reliability calculation [56].

\section{Results and Discussion}

The most famous is calculating reliability by the average group failure rates of elements [5761]. To carry out the calculation, it is necessary to know: the types of elements, the failure rate of elements of various types $\lambda$, and the number of elements of each type Ni included in the system. Consideration of operating conditions MWNFC comes down to choosing the types of elements capable of operating under specified operating conditions. 


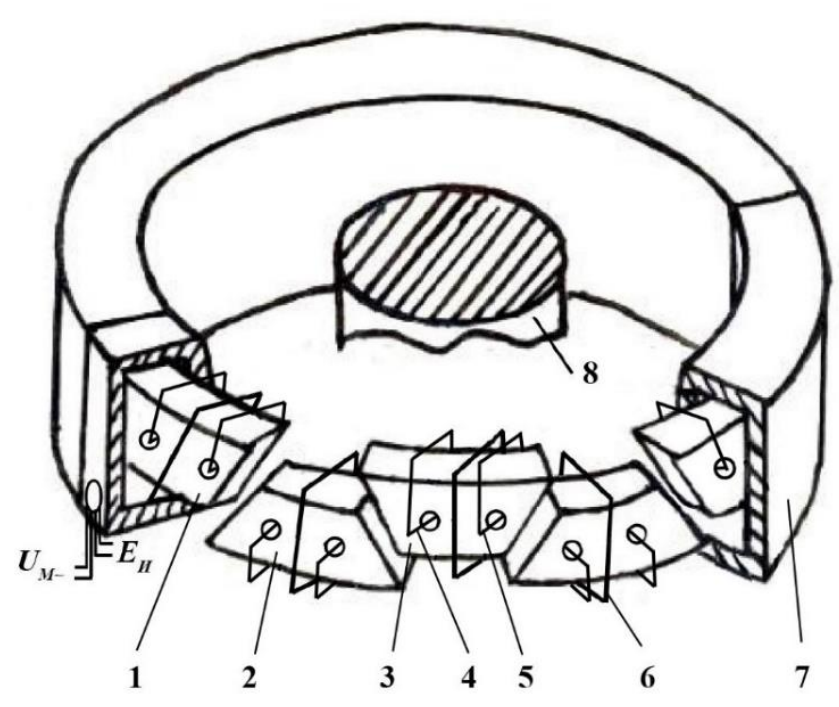

Fig. 1. Magnitomodulation contactless wide-range converter high currents control and management systems

At the design stage, the number of elements included in MWNFC is usually already known. The considered method of calculating the reliability makes it possible to determine the mean time between failures $\mathrm{T}_{\mathrm{av}}$ and the probability of failure-free operation $\mathrm{P}(\mathrm{t})$ MWNFC [33]. The calculation is performed in the following order:

- all elements MWNFC divide into several groups $n$ with approximately the same failure rate $\lambda_{\mathrm{i}}$ within the $\mathrm{i}$-th group and calculate the approximate number of elements in each group $\mathrm{N}_{\mathrm{i}}$;

- according to the tables, the average value of the failure rate of the elements of each group is found $\lambda i$;

- calculate the product $N i \lambda i$;

- calculate the total failure rate of MWNFC for all $\mathrm{n}$ groups of elements:

$$
\lambda=\sum_{i=1}^{n} N_{i} \lambda_{i}
$$

- determine the MWNFC:

$$
T_{c p}=\frac{1}{\sum_{i=1}^{n} N_{i} \lambda_{i}}
$$

- find the probability of failure-free operation of MBShPT in time $\mathrm{t}$ : 


$$
P(t)=e^{-t \sum_{i=1}^{n} N_{i} \lambda_{i}}
$$

For small values $\left(\sum_{i=1}^{n} N_{i} \lambda_{i}\right)^{-1}$ to find $\mathrm{P}(\mathrm{t})$, it is convenient to use the approximate formula

$$
P(t) \approx 1-t \sum_{i=1}^{n} N_{i} \lambda_{i}
$$

The reliability of the developed MWNFC will be determined using the above methodology. Therefore, it is important to find the failure rate $\mathrm{k}$ when determining the reliability of MWNFC. The failure rate of the entire MBShPT can be determined according to [9] as the sum of the failure rates of individual elements and nodes. For this purpose, MBShPT is represented in the form of the following elements:

\begin{tabular}{|c|c|c|c|}
\hline \multirow{2}{*}{$\begin{array}{c}\text { The elements } \\
\text { converter }\end{array}$} & \multicolumn{3}{|c|}{ Converter assemblies } \\
\cline { 2 - 4 } & Winding & Insulation & Solder connection \\
\hline Modulation system & $0.0510^{-6} \mathrm{n}$ & $0.510^{-6} \mathrm{n}$ & $0.00410^{-6}(\mathrm{n}-1)$ \\
\hline Measuring system & $0.110^{-6} \mathrm{n}$ & $0.510^{-6} \mathrm{n}$ & $0.00410^{-6}(\mathrm{n}-1)$ \\
\hline Power supply & - & $7.210^{-6}$ & - \\
\hline Potentiometer & - & $1.410^{-6}$ & - \\
\hline Resistance & - & $0.0410^{-6}$ & - \\
\hline $\begin{array}{c}\text { The total failure rate of } \\
\text { converter elements }\end{array}$ & $\begin{array}{c}\lambda 0=0.15 \mathrm{n} 10^{-6} \\
{\left[\text { hour }^{-1}\right]}\end{array}$ & $\begin{array}{c}\lambda \mathrm{i}=(8.64 \mathrm{n}) 10^{-6} \\
{\left[\text { hour }^{-1}\right]}\end{array}$ & $\begin{array}{c}\lambda \mathrm{p}=0.008(\mathrm{n}-1) 10^{-6} \\
{\left[\text { hour }^{-1}\right]}\end{array}$ \\
\hline
\end{tabular}

Failure rates table modulation systems, measurement systems, power supply, potentiometer and resistance. In this case, the MWNFC nodes include winding, winding insulation and soldering of the windings. For simplicity, the manufacture of the transducer has a modulation winding and a measuring winding to be performed for each ferroelement separately. Then carry out the soldering connection of all winding leads. Therefore, when determining the failure rate, it is necessary to consider the number of ferroelements. The values of the failure rates according to the data of the "Gene" company (USA) [57] are given in the table.

The total failure rate of the converter elements is determined by the expression

$$
L=L O+L \imath+L \pi=(8.632+1.158 v) 10^{-6},\left[\eta 0 u \rho^{-1}\right]
$$

It can be seen from the last expression that the failure rate of MBShPT depends on the number of ferroelements $n$.

Let's define the reliability of MBShPT according to the formula (3), taking into account (5), taking $\mathrm{psr}=20$ and $\mathrm{t}=103$ hours, in the form:

$$
P(t)=e^{-t \sum_{i=1}^{n} N_{i} \lambda_{i}}=0.998
$$

Taking into account catastrophic failures $\mathrm{PK}_{\mathrm{K}}=0.9989$ [55], the total reliability of MWNFC will be determined

$P=P \Pi \cdot P \kappa=0.9980 \cdot 0.9989=0.9969$. 
Gradual failures resulting from aging, the aggressiveness of the environment, changes in its temperature are characterized by a gradual deterioration of the specified parameters of the MWNFC, which change the parametric reliability of the MWNFC.

Comparing the obtained values of reliability of MWNFC with the values of similar reliability of DC transformers, one can indicate their compliance. It is also possible to note the increased reliability of chemical devices with MWNFC and, consequently, ACS TP in electrochemistry, in comparison with similar chemical devices and systems using shunts as converters of large direct currents.

\section{Conclusions}

Wide-range magnetic modulation non-contact converters of high direct currents have been developed for modern control and management systems in water supply in irrigation, land reclamation, as well as renewable energy sources, industry, railway transport, in the agroindustrial sphere, in GIS technologies, and, in particular, in digital coverage and database visualization, as well as for the verification of electric meters at the place of their installation, characterized by an extended controllable range of convertible direct currents with small dimensions and weight, increased accuracy and sensitivity, simplicity and manufacturability of the design with low material consumption and cost, and the possibility of contactless control of direct and alternating currents with an error of $1.5 \%$. The issues of reliability of magnetic modulation contactless converters are considered. The results of their research have been obtained. It is shown that the reliability of wide-range magnetomodulation noncontact converters of high direct currents is 0.998 and considering catastrophic failures, their total reliability is 0.9969 .

\section{References}

1. Kazakov M K Methods and means of measuring high voltages and high currents in electric power p. 32, Russian, Ulyanovsk, (1998)

2. Wenlong Z, Minxi Z, Guoliang Y, Petukhov V, Vsévolod Mymrin and Evangelos G. Flow Resistance in Dredged Soil under a Vacuum Preloading System with Vertical Drainage Boards Coastal Education and Research Foundation Vol. 36 No 2 pp. 327338, (2020)

3. Krämer W. Gleichstrom Wandlerschaltung hoher Genauigkeitl für wellige Gleichstrom ETZ-A No 18 pp. 28-33, German, (1996)

4. Plakhtiyev A.M. and Akhmedov S.U. Condition of application and development of non- contact ferromagnetic converters in electrochemistry and metallurgy Eighth World Conference on Intelligent Systems for Industrial Automation. WCIS - 2014 ISBN: 3-933609-8, pp.326-329, (2014)

5. Lappe F Ein neues Me§gerät für hohe Gleichström-Chemi-Ingenier-Technick, , Bd. 42, No 19, pp 12281229 (1998)

6. Amirov S F , Safarov A M, Rustamov D Sh and Ataullaev N O High-current electromagnetic converters for traction power supply systems, Tashkent: Fan, p.279 (2019)

7. Ziegler S, Woodward R and Herbert H.C. Current Sensing Techniques: A Review. IEEE Sensors Journal 9(4), pp 354-376 (2009)

8. Danilov A 2004 Modem industrial current sensors, Modem electronics No 10 pp. 38 43

9. Bolotin O, Portnoy G and Razumovsky K 2016 Modem sensors for measuring current and voltage, ISUP, No 1(61) pp 18-25 
10. Gilardi M 2013 New Horizons of Hall Effect Current Sensor Technology, Power Electronics, No 3 pp 48-52

11. Wu Y, Liu Y, Li F, Zhou Y, Ding J and Li Run-Wei Sensors and Actuators B. Chemical 276 pp. 540-544 (https://doi.org/10.1016/i.snb.2018.08.083) (2018)

12. Pinar A, Wijnen B, Anzalone G.C, Havens T.C, Sanders P.G, Pearce J.M. and Sens J. Low-cost open-source voltage and current monitor for gas metal arc weld 3D printing 10.1155/2015/876714, (2015)

13. Safarov A.M. The use of current transducers in systems of technical diagnostics of electrical equipment - Proceedings of the International scientific and technical conference "Current status and prospects for the development of energy" pp. 173-175, Tashkent, (2006)

14. Makoto T, Yasunori O, Michihira I, Chihiro Y and Jianging W Non-Contact Measurement Method for High Frequency Impedance of Load at the End of Wire Harness, SAE International Journal of Engines, 10 No. 4 pp 2034-2039, (2017)

15. "Charging directions: EV owners tell all". ReNew: Technology for a Sustainable Future. 2017, No 139, SUSTAINABLE TRANSPORT SPECIAL pp 53-63

16. Ray T, Smith F, Jjunju P M, Young S, Stephen Taylor and Simon Maher 2016 A physical model for low-frequency electromagnetic induction in the near field based on direct interaction between transmitter and receiver electrons Mathematical, Physical and Engineering Sciences 472 No 2191 pp 1-13

17. 2016 Power Electronics Applied to Industrial Systems and Transports Vol 5 Measurement Circuits, Safeguards and Energy Storage 1 - Sensors for Power Electronics pp 1-73 doi.org/10.1016/B978-1-78548-033-1.50001-3

18. Mohammad S A, Aqueel A, Zeeshan A K, Yasser R, Rakan C Ch, Imran K and Samir M Al- Shariff 2018 A Bibliographical Review of Electrical Vehicles (xEVs) Standards SAE International Journal ofAlternative Powertrains Vol 7 No 1 pp.63-98

19. Khushbokov B.Kh. Multi-limit current transformers for control systems ofdevices for power supply of railway transport Tashkent, (2010)

20. Borkman D. Hochstrommessungmit Hallgeneratoren. - Elekrie, Bd. 18 No 2, p. 4650, (1997)

21. Abduvaliev A.A., Sadikov A.B. and Gaziev G.A. Ustroystvo poverki schetchikov elektricheskoy energii na meste ustanovki Pat. FAP 00414 Bis/ No 10 (90) p. 77, (2008)

22. Abduvaliev A.A, Sadikov A.B and Gaziev G.A. «Izmeritel'niy preobrazovatel' moshnosti peremennogo toka» Pat. FAP 004492, Byul. No 9 (101) p 45 (2009)

23. Duc N H and Huong D T 2008 Magnetic sensors based on piezoelectricmagnetostrictive composites J. Alloys and Compounds vol 449 pp 214-218

24. Jun P, Shuhai J, Jiaming B, Shuo Zh, Jianben L and Xing Zh 2019 Recent Progress on Electromagnetic Field Measurement Based on Optical Sensors US National Library of Medicine and National Institutes ofHealth doi: 10.3390/s19132860.

25. Yuki T N 2016 Electromagnetic noncontacting measuring apparatus, US patent No 5234844, ICI G01R 27 / 04, NCI 324 - 58 from 18.11.

26. Bardahl N Einrichtung zur Erfassung des Belastungsstromes in Hochstromanlagen, German patent No 3148654, Km. 21e36/01 from 28.11.

27. Eadie E M Complete specification improvements in multi-range hook-on electrical indication instrument, UK patent No 3966443, NCI GIU from 21.12. 
28. Standard Telefones and Cables LTD Current monitoring circuits including Hall Effect devices, UK patent No 4575111, ICI G01R 19 / 165, NCI GIU from 17.09. No 4773

29. Tokyo Shibaura Transducers. UK patent No 3036984, ICI G01R 19 / 22, NCI GIU from 02.07., No 4968 (2017)

30. Meierovich E.A. and Andreevskaya L. Dispositif paur la mesure de I intesite du courant. French patent No 4347944, ICI G01R from 24.02. No 2, (2017)

31. Bernard G A 2000 Transducteur electrique comportani un moyen de codage dun parameter du transducteur, French patent No 3955731, ICI G01D 18 / 00 3 / 04; G01F 25 / 00 from 02.01.No 1

32. Reich Ernö. Elektricky mërici pristroj, Czech patent No 2145015, ICI 21e36 from 15.04. (2018)

33. Zoltàn L. Aramlökést mérö müszer, Hungarian patent № 2146340, ICI 21e 29-36 from 30.11, (2015)

34. Hitachi Ltd., Chiyoda-ku Tokyo 100 (JP) Magnetoelectrical transducer. Japan patent No 3257766, ICI G01D 5 / 16 from 18.08. No 33, (2017)

35. Brodovsky V.N. and Korzhanov B.M. Current transformer No A.C. 3592239 , MHK21e36 - from 5.01. Bulletin 4, (2017)

36. Steiglitz K 2019 Signal Standardization. In The Discrete Charm of the Machine: Why the World Became Digital (pp 22-42). Princeton; Oxford: Princeton University Press. doi: $10.2307 /$ j.ctvc77c2g.6

37. Michael J, Lenaeus, Tamer M, Gamal El-Din, Christopher Ing, Karthik Ramanadane, Regis Pomes, Ning Zheng and William A. Catterall Structures of closed and open states of a voltage-gated sodium channel Proceedings o[ the National Academy of Sciences of the United States ofAmerica. 114 No 15 pp E3051-E3060, (2017)

38. Evangelos H "Magnetic Sensors" A special issue of Sensors (ISSN 1424-8220) School of Electrical and Computer Engineering, National Technical University of Athen, 15780 Athens, Greece, (2018)

39. Wei L, Bing Liang, Zhenyuan Jia, Di Feng, Xintong Jiang, Xiao Li and Mengde Zhou 2018 High-Accuracy Calibration Based on Linearity Adjustment for Eddy Current Displacement Sensor Key Laboratory \%r Precision and Non-traditional Machining Technology of the Ministry Education 18(9) pp. 2842, https://doi.org/10.3390/s18092842

40. Ripka P 2004 Current sensors using magnetic materials Journal of Optoelectronics and Advanced Materials, 6 No 2, pp. 587-592

41. Arya Krishna S and Lizy Abraham Analysis of Different Hall Effect Current Sensors for Space Applications IJISET — International Journal of Innovative Science, Engineering and Technology 1(5), (2014)

42. Laimer G and Kolar J W 2005 Design and experimental analysis of a DC to $1 \mathrm{MHz}$ closed loop magnetoresistive current sensor. Twentieth Annual IEEE Applied Power Electronics Conference and Exposition pp. 1288-1292 10.1109/APEC.2005.1453172

43. Maria-Alexandra P, Jean-Michel S and Maher K 2013 Comparative Study on the Performance of Five Different Hall Effect Devices Sensors US National Library of Medicine and National Institutes of Health 13(2) pp. 2093-2112, doi: 10.3390/s130202093

44. Yoshihiro Konno and Masaru S, Electric current measure apparatus. Japan patent ICI G01R 1 from 21.05. No CN204154795U, Japan, 2009 
45. Chjan Li. Stripping electrical measuring one meter. ICI G01R 19 from 02.11. No CN204154795U, China, (2015)

46. Michel Lynn and John Shie. Power amplifier saturation detection. ICI G01R from 03.05. No US10224917B2, Korea, (2019)

47. Andreas Jurisch 1995 Method of measuring current in a conductor in an ac transmission network ICI G01R from 03.08 No WO19945020765A1 (Italy)

48. Horst K and Frank K. Highly accurate current measurement. ICI G01R from 13.02 No EP2821799A1 (European patent office), (2019)

49. Rudolf Gati and Markus Abplanalp Configuration of magnetoriesistire sensors for current measurement ICI G01R from 22.07 No ES2591283T3, Spain, (2008)

50. Woifgang $\mathrm{G}$ and Jean-Pierre $\mathrm{D}$. Method of opening a bypass switch of a high voltage direct current network. ICI G01 from 21.09 No CA284893OC, Canada, (2011)

51. Gurtovtsev A L 2010 Optical transformers and current converters Principles of operation, device, characteristics Electrical Engineering News No 5 pp. 48-52

52. Plakhtiev A M 2017 Effective information contactless converters for modern control systems in the agricultural sector Int. Scientific and Practical Conf. "Agricultural science - to agriculture" pp. 37-39 (Russian, Barnaul)

53. Sotskov BS Fundamentals of the theory and calculation of the reliability of elements and devices of automation and computing technology. - M .: Higher school, p. 456, (1970)

54. Rakhmonov S., Umurzakov U., Rakhmonov K., Bozarov I., Karamatov O. Land use and land cover change in Khorezm, Uzbekistan. E3S Web of Conferences, 227, 01002 , (2021)

55. Aripdzhanov M.K., Shipulin Yu. G. Reliability and reliability of digital devices and systems. - Tashkent: TGAI, p.76 (2003)

56. Umurzakov U., Mamatov F., Aldoshin N., Mirzaev B. Exploration of tillage technologies in the Republic of Uzbekistan, IOP Conference Series, Earth and Environmental Science, 614(1), 012168, (2020)

57. Lipchin Ts. N., Lipchin L. Ts. Reliability of aircraft navigation and computing devices. - Moscow: Mashinostroenie, p.196, (1991)

58. Umurzakov U., and Djuraev B. Prediction of prices for agricultural products through markov chain model, International Journal of Psychosocial Rehabilitation, 24(3), pp. 293-303, (2020)

59. Yarlykov N. E. Improving the efficiency of reliability control. - M .: Radio and communication, p. 192, (2003)

60. Umurzakov U., Mirzaev B., Salahodjaev R., Isaeva A., and Tosheva S. Energy consumption and economic growth: Evidence from post-communist countries. International Journal of Energy Economics and Policy, 10(6), pp. 59-65, (2020)

61. Sagdulin E.R. Course "Diagnostics and reliability of EPO", p. 86, Tashkent, TGAI, (2008) 